\title{
'n Elektroglottografiese Analise van Sekere Stemparameters: Normatiewe Aanduidings
}

\author{
Kobie Cloete \\ Emily Groenewald \\ Anita van der Merwe \\ Departement Spraakheelkunde en Oudiologie \\ Universiteit van Pretoria \\ Jean Badenhorst \\ Departement Statistiek \\ Universiteit van Pretoria
}

\begin{abstract}
OPSOMMING
'n Omvattende stemevaluasie behels meer as net die evaluasie van perseptuele en organiese aspekte. Vir' $n$ volledige stemevaluasie is dit belangrik dat verskeie objektiewe metings die diagnostiese battery aanvul. Ten einde normatiewe riglyne vir sekere kwantitatiewe elektro-glottografiese metings vir die Universiteit van Pretoria se Spraaknavorsingslaboratorium daar te stel, is 25 mans en 25 dames met perseptueel normale stemme, uit 'n ouderdomspektrum van 8 tot 80 jaar, ondersoek met betrekking tot gemiddelde fundamentele frekwensie, piek-tot-piek frekwensiéfluktuasie, piektot-piek amplitudefluktuasie en harmoniek/ruis-verhouding. Resultate dui aan dat al hierdie parameters sensitief is vir verandering in stemproduksie as gevolg van veroudering, vokaal-en luidheidsveranderinge. Die waarde van die verkreë data vir navorsing en die kliniese praktyk word bespreek.
\end{abstract}

\section{ABSTRACT}

A comprehensive voice evaluation comprises more than just the evaluation of perceptual and organic aspects. Objective voice analysis should supplement the diagnostic battery. In order to obtain normative indications for the Speech Research Laboratory at the University of Pretoria, 25 men and 25 women ranging in age from 8 to 80 years and with perceptually normal voices were tested with regard to fundamental frequency, cycle to cycle frequency fluctuation (jitter), cycle to cycle amplitude fluctuation (shimmer) and harmonic/noise ratio. Results indicate that these parameters are sensitive to changes in voice production caused by ageing, changes in loudness and the production of different vowels. The implications of these results for research and clinical practice are discussed.

'n Omvattende stemevaluasie behels meer as net die evaluasie van perseptuele en organiese aspekte. Vir'n volledige stemevaluasie is dit belangrik dat verskeie objektiewe metings die diagnostiese battery anvul (Gould, 1988; Glaze, Bless \& Susser, 1990). Stemlaboratoria, bestaande uit onder andere verskeie akoestiese meetinstrumente, het die afgelope dekade vinnig toegeneem (Gould, 1988). Die ideale stemlaboratorium verskaf optimale informasie vir diagnose en behandeling van 'n stempasiënt en kan gebruik word vir verdere navorsing om steeds meer gesofistikeerde pasiëntsorg te verseker (Sataloff, Spiegel, Carroll, Darby, Hawkshaw \& Rulnick, 1990). Die Spraaknavorsingslaboratorium van die Universiteit van Pretoria beskik oor die nodige instrumentasie vir die uitvoer van elektroglottografiese (EGG) metings, maar weens 'n gebrek aan normatiewe data is dit moeilik om hierdie tegniek sinvol aan te wend. Hierdie behoefte aan norme blyk ook uit die literatuur. (Wilcox \& Horii, 1980; Hollien, 1987; Colton \& Conture, 1990; Fitch, 1990; Glaze et al., 1990; Sataloff et al., 1990). Hierdie studie beoog dus die uitbreiding van stemanalisemetodiek deur die daarstelling van normatiewe riglyne vir EGG-metings, vir gebruik met normale en patologiese stemme.

Die elektroglottograaf is 'n objektiewe, nie-indringende meetinstrument wat gebruik word om stembandaktiwiteit te ondersoek sonder veel ongemak of inmenging met fonasie (Gould, 1988). Dit meet die elektriese stroom tussen twee elektrodes aan weerskante van die larinks soos wat dit deur die nekweefsel en stembande beweeg (McFarlane \& Watterson, 1991). Die resultaat is ' $n$ weerstandsgolfpatroon. Normale stembandvibrasie produseer' $n$ reeks relatief eweredige weerstandsgolwe en word as 'n gelykmatige klank gehoor, ten spyte van minimale fluktuasie in die golfpatroon (McFarlane \& Watterson, 1991). Die stembande is 2 onafhanklike vibrators wat elk funksioneer op grond van die inherente fisiologiese eienskappe (by. stembandmassa, -spanning, spieraktiwiteit, neurale aktiwiteit en kardio-vaskulêre 
betrokkenheid) daarvan. Indien die gekombineerde werking van die twee afsonderlike stembande 'n reeks weerstandsveranderinge tot gevolg het wat varieër in terme van tyd en/of amplitude, word die stem as grof, skor of hees waargeneem (Horii, 1980; Hollien, 1987; Orlikoff \& Kahane, 1991).

Akoestiese metings, naamlik piek-tot-piek frekwensiefluktuasie ("jitter") en piek-tot-piek amplitudefluktuasie ("shimmer") reflekteer onderskeidelik die stabiliteit en reëlmaat van stembandvibrasie. Lae piektot-piek frekwensiefluktuasie (PPFF)-waardes dui dus op relatief hoë stabiliteit in die frekwensie van stembandvibrasie en lae piek-tot-piek amplitudefluktuasie (PPAF)-waardes dui op 'n hoë mate van reëlmaat in die amplitude van stembandvibrasie (Orlikoff en Kahane, 1991). Uit die literatuur blyk dit dat PPFF en PPAF baie hoër waardes by growwe, skor, en hees stemme het. Piek-tot-piek fluktuasies is ook baie groter in patologiese stemme as in normale stemme (Horii, 1980; Hollien, 1987; Brown, Morris \& Michel, 1989; Linville, Korabic \& Rosera, 1990). Onlangs is 'n kwantitatiewe stemanalise-program vir die Kay DSPSonagraph (model 5500) beskikbaar gestel. Hierdie program bepaal, m.b.v. 'n elektroglottograaf, outomaties gemiddelde fundamentele frekwensie (gem. fo), PPFF, PPAF en gee 'n harmoniek/ruis-verhouding (wat 'n aanduiding gee van die hoeveelheid ruis of heesheid in die stem).

Navorsing dui daarop dat 'n akoestiese analise van die stem moontlik die eerste akkurate informasie aangaande patologiese verandering in die larinks verskaf (Baken, 1987). Veroudering impliseer nie noodwendig 'n patologiese toestand nie, maar normale anatomiese en fisiologiese verandering tree wel met veroudering in (Hollien, 1987). Veranderinge in perseptuele en akoestiese eienskappe in die verouderende stem kan aan ouderdomsverwante anatomiese en fisiologiese veranderinge op molekulêre, sellulêre en orgaanvlak toegeskryf word, wat dwarsdeur die hele liggaam plaasvind (Aronson, 1985; Chodzko-Zajko \& Ringel, 1987; Biever \& Bless, 1989; Orlikoff, 1990a). Volgens Orlikoff (1990a) word die fonatoriese sisteem die meeste van enige komponent in die spraakmeganisme deur veroudering geaffekteer. Dit blyk dus dat ' $n$ behoefte aan bruikbare norme vir verskillende ouderdomsgroepe bestaan.

\section{METODE}

\section{DOELSTELLINGS}

Die doel van die studie is die uitvoering van 'n EGGanalise van spesifieke stemparameters van sprekers met perseptueel normale stemme, ten einde normatiewe riglyne daar te stel. Die subdoelstellings is om die invloed van ouderdom asook vokaal- en luidheidsveranderinge op die volgende stemparameters na te gaan:

Gemiddelde fundamentele frekwensie (gem. fo) by manlike en vroulike sprekers

- Piek-tot-piek frekwensiefluktuasie (PPFF)

- Piek-tot-piek amplitudefluktuasie (PPAF)

- Harmoniek/ruis-verhouding (H/R-verhouding)

\section{NAVORSINGSONTWERP}

Hierdie studie behels 'n kruisseksie-opname (Guy, Edgley, Arafat \& Allen, 1987) deur middel van die korrelatiewe navorsingstegniek (Smit, 1983). 'n Kwotasteekproef word gebruik om proefpersone te selekteer. Proefpersone word sodoende in verskillende kombinasies van ouderdom en geslag georden, om 'n objektiewe beeld van die stemeienskappe'van persone van verskillende geslagte, in spesifieke ouderdomsgroepe, langs 'n ouderdomskontinuum te verkry. Hierdie tipe navorsingsontwerp het dan ook die voordeel dat veranderlikes onder natuurlike omstandighede bestudeer kan word en die ko-variasie tussen die onderskeie veranderlikes ondersoek kan word. Informasie wat deur die opname-studie verkry word, kan na die hele populasie veralgemeen word (Guy et al., 1987). Hierdie tipe studie is dus voordelig om te gebruik vir die opstel van'n normbasis.

\section{PROEFPERSONE}

\section{Kriteria vir die seleksie van proefpersone:}

\section{Ouderdom:}

Aangesien die beplande databasis vir 'n ouderdomspektrum opgestel word, is proefpersone binne die volgende vyf oudersomsintervalle ondersoek:

8 tot 10 jaar - Die kinders moet geen tekens van puberteit toon nie (Glaze et al., 1990 ), aangesien spesifiek 'n prepuberteitsanalise van die stem gemaak word.

19 tot 23 jaar -Hierdie post-puberteitsanalise van die stem behoort optimale stembandfunksionering te reflekteer, aangesien maksimum effektiwiteit in liggaamlike funksionering ongeveer in hierdie tydperk plaasvind (Orlikoff, 1990a).

30 tot 40 jaar-Orlikoff (1990a) postuleer dat liggaamlike funksionering toenemend vinniger begin afneem vanaf ongeveer dertigjarige ouderdom. Deur hierdie groep in te sluit kan die aanvang van stemveroudering gemonitor word.

50 tot 60 jaar-Hierdie kategorie word ingesluit om die status van stembandfunksionering te evalueer net voor werklike veroudering begin intree.

70 tot 80 jaar:-Na die sesde lewensdekade is dit moeilik om groepsgemiddelde op persone toe te pas, selfs al vind normale veroudering plaas (Orlikoff, 1990b). As gevolg van baie kontroversie in die literatuur (Shipp \& Hollien, 1969; Horii \& Ryan, 1981; Hollien, 1987), blyk dit nodig te wees om aparte norme, spesifiek vir hierdie ouderdoms-groep, daar te stel. 


\section{Ander faktore:}

5 Manlike en 5 vroulike proefpersone per ouderdomsgroep is geselekteer op grond van perseptueel normale stem. Geen relevante mediese probleme mag teenwoordig wees nie. Persone mag nie meer as 20 sigarette per dag rook nie, moet oor normale gehoor beskik, nie oormatig oorgewig wees nie en nie medikasie gebruik wat 'n uitdrogingseffek op die larinks het nie (Orlikoff, 1990a; Hollien, 1987; Horii, 1980; Fitch, 1990; Baken 1987).

\section{MATERIAAL}

Die vokale /a:/ en /i:/ word geselekteer vir hierdie studie. Uit die literatuur blyk dit dat hierdie twee vokale die meeste vir EGG-opnames gebruik word (Childers \& Lee, 1991). Die vokale /a:/ en /i:/ verteenwoordig die grootste moontlike fisiologiese omvang vir vokaalproduksie (Fitch, 1990). Aangesien persone met stempatologie dikwels probleme ondervind met luidheidsveranderings, word elke vokaal ook met verhoogde luidheid geproduseer sodat 'n basis verkry kan word waarmee patologiese luidheidverandering vergelyk kan word.

\section{APPARAAT}

Die volgende apparaat is gebruik vir die stemopnames: "Portable Electro-Laryngograph" met elektrodes, Electro-Voice Mikrofoon Model 631B, Kay DSP Sonagraph Model 5500 en NEC Multisync II vertoonskerm. Die opstelling van die apparaat is gedoen soos voorgestel in die handleiding van die sonagraaf (Kay Elemetrics Corp., 1989). Die analise is met behulp van die outomatiese stemanaliseprogram, model 5625 , van die DSP Sonagraph gedoen.

\section{PROSEDURE VIR DATAVERSAMELING}

Die plasing van die elektrodes op die proefpersoon se larińks het volgens die prosedure, soos aanbeveel deur' McFarlane en Watterson (1991) en Colton en Conture (1990), geskied. Optimale elektrodeplasing en opname-instellings is telkens getoets deur voorafgaande proefopnames (Kay Elemetrics Corp., 1989). Die vokaal /a/ en / $/$ / is op dieselfde wyse geproduseer, opgeneem en ontleed. Elke vokaal is vir 2 sekondes geproduseer by normale gesprekstoonhoogte en -luidheid, gevolg deur 'n produksie van 2 sekonde's teen verhoogde luidheid. Elke uiting is 3 maal herhaal en afsonderlik ontleed, om sodoende die invloed van intrapersoonlike variasie te bekamp.

\section{PROSEDURE VIR DATA-ANALISE}

Die analiseprosedure by elke uiting, het bestaan uit die afbakening van ongeveer 100 siklusse van 'n stabiele, middelgedeelte van die Lx-sein, soos op die skerm geposisioneer. (Horii, 1980; Linville et al., 1990). Die onderskeie parameters is dan outomaties bereken deur die aktivering van die stemanaliseprogram.

- Die meting van gemiddelde fundamentele frekwensie

Fundamentele frekwensie word bepaal deur die vibrasiespoed van die stembande en bepaal die toonhoogte van fonasie. Die gemiddelde fo is telkens bereken vir ' $n$ periode van ongeveer 100 siklusse.

\section{Die meting van PPFV}

Lieberman (1963) definieer PPFF ("jitter") as die siklus-tot-siklus fluktuasie in fundamentele frekwensie. Die stemanaliseprogram gebruik 'n manipuleerde vorm van Koike se formule (Kay Elemetrics Corp., 1989) om PPFF te bereken. Resultate word as persentasie (\%) weergegee.

\section{- Die meting van PPAF}

PPAF ("shimmer") of soos Horii (1980) dit definieer, siklus-tot-siklus amplitudefluktuasie, word in hierdie studie bepaal deur die verskil tussen die mees positiewe en mees negatiewe pieke te bereken (Kay Elemetrics Corp., 1989). Die verkreë PPAF-waardes word in desibel (dB) uitgedruk.

\section{Die meting van harmoniek/ruis-verhouding}

Die H/R-verhouding druk die verskil in $\mathrm{dB}$ uit tussen die harmoniese en ruiskomponente in die afgebakende deel van die stemgolf. Dus, hoe kleiner die verskilwaarde tussen die amplitude van die harmoniese komponent en die amplitude van die ruis-

- komponent, hoe kleiner is die H/R-verhoudingswaarde. 'n Klein H/R-verhouding dui op 'n hoë mate van ruis in die stem en word as heesheid gehoor (Yumoto, 1988).

\section{PROSEDURE VAN DATAVERWERKING}

'n Variansie analise is op die finale data gedoen met behulp van PROC ANOVA en die SAS-programpakket. Hierdie analise het getoets vir enige betekenisvolle verskille tussen die verskeie veranderlikes. Die peil van betekenis was bepaal by $p<0.05$. Uit die data is statistiese gegewens aangaande die verskeie veranderlikes verkry om sodoende frekwensieverdelings, gemiddeldes, standaardafwykings, minimum- en maksimumwaardes te bereken. Uit die finale data is vertrouensintervalle ook opgestel vir verskeie veranderlikes. 'n 95\% vertrouensinterval is gekonstrueer sodat met $95 \%$ sekerheid gesê kan word dat hierdie interval wel die populasie-gemiddeld sal bevat (waar populasie beduie op die totale groep van persone waarop hierdie studie betrekking het). Hierdie interval is gebruik om 'n skatting te maak van die onbekende populasiegemiddeld (Steyn, Smit \& Du Toit, 1987; Bowermann \& O'Connel, 1990).

\section{RESULTATE EN BESPREKING}

Die resultate word beskryf en bespreek aan die hand van die onderskeie subdoelstellings.

\section{GEMIDDELDE FUNDAMENTELE FREKWENSIE}

- Ouderdomsverwante verandering in gemiddelde fundamentele frekwensie van mans en vroue.

Die gem. fo van die mans- en vrouegroep verskil statisties betekenisvol op 'n peil van $5 \%$. Die resultate vir die 2 groepe word dus afsonderlik verskaf. In figuur 1 word die gem. fo van mans in verskillende ouderdomsgroepe weergegee vir produksie van /a:/ en /i:/ met normale en verhoogde luidheid. 


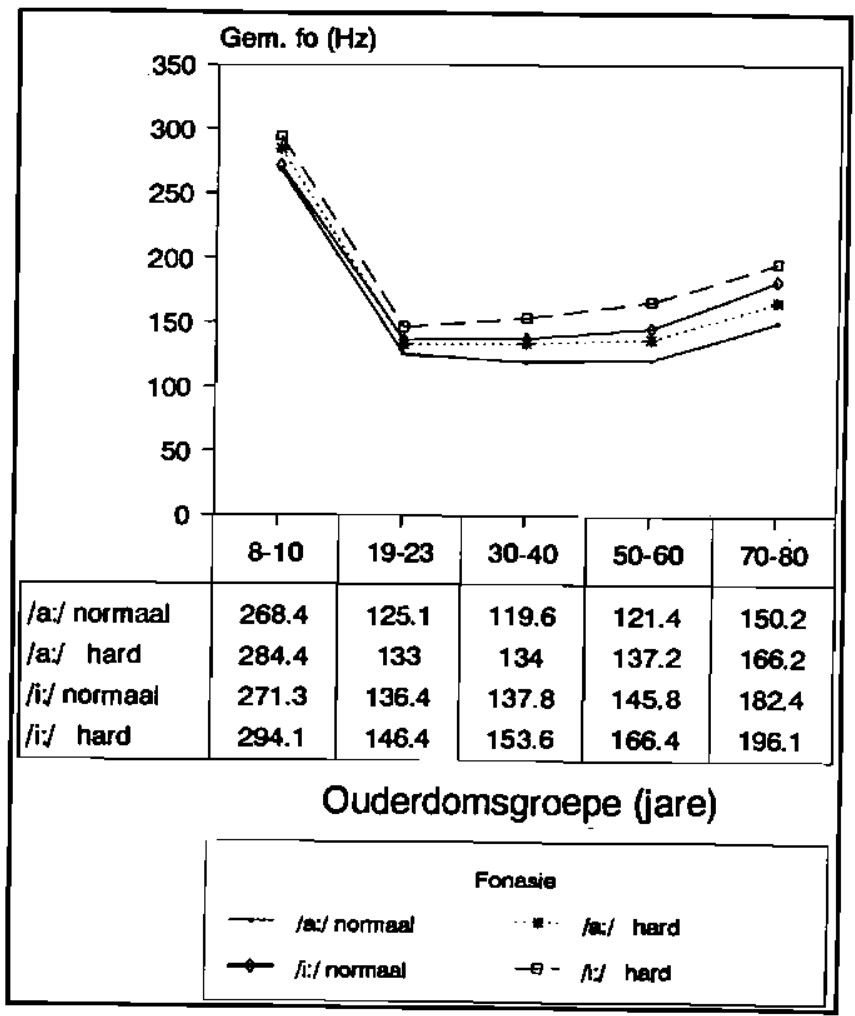

Figuur 1: Die verandering in gem. fo van mans in verskillende ouderdomsgroepe tydens produksie van /a:/ en /i:/ met normale en verhoogde luidheid.

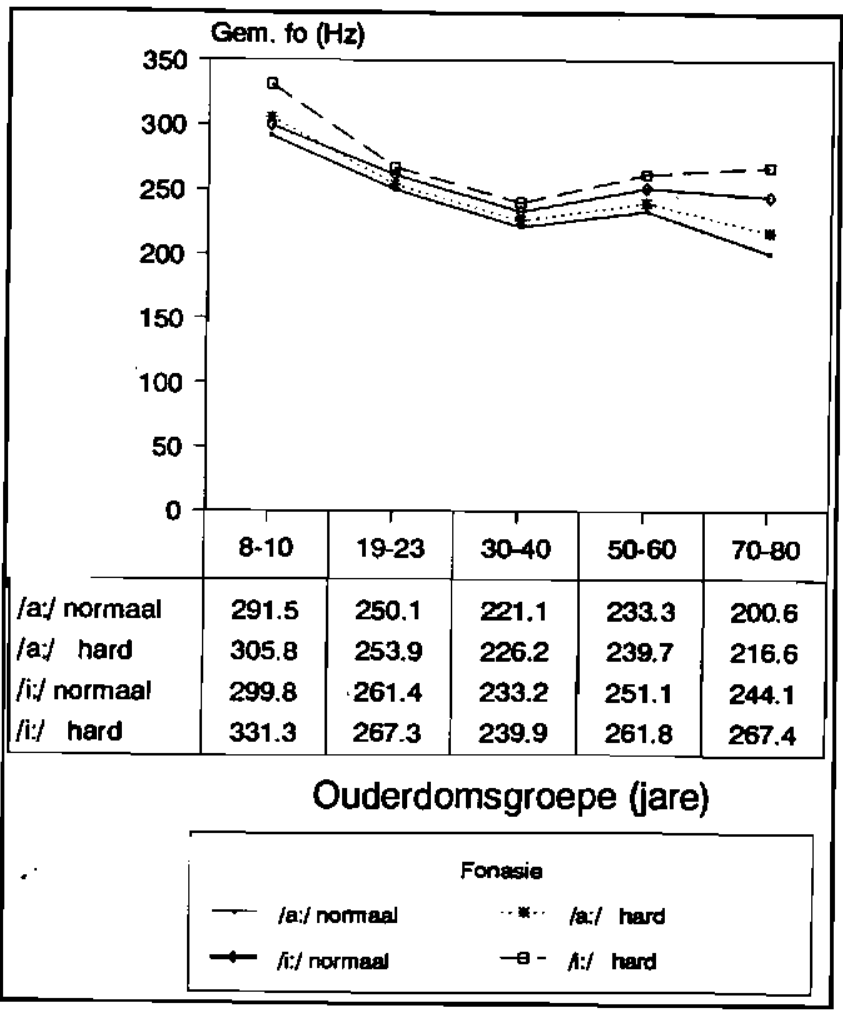

Figuur 2: Die verandering in gem. fo van vroue in verskillende ouderdomsgroepe tydens produksie van die vokale /a:/ en /i:/ met normale en verhoogde luidheid.
Daar is 'n skerp daling in gem. fo na puberteit. Slegs die 8-10 jaar groep verskil statisties, op 'n $5 \%$ peil van betekenis, van die ander ouderdomsgroepe. Die verlaging in fo na puberteit, is die logiese gevolg van fisiese groei van die fonasiestruktuur. Dit word gevolg deur'n neiging tot verhoging in gem. fo met veroudering, wat moontlik toegeskryf kan word an ouderdomsverwante veranderinge wat in die larinks plaasvind, bv. verdunning van die stembande a.g.v. atrofie, dehidrasie van die laringale mukosa, vermindering in die elastisiteit van die laringale ligamente, toenemende ossifikasie en kalsifikasie van die kraakbenige strukture van die larinks en afname in sentrale senuweestelselkontrole (Aronson, 1985; Chodzko-Zajko \& Ringel, 1987; Orlikoff, 1990b). Die gem. fo waardes verkry in die huidige studie korreleer met die resultate van ander navorsers (Aronson, 1985; Colton \& Casper, 1990; Childers \& Lee, 1991).

In figuur 2 word die gem. fo van vroue in verskillende ouderdomsgroepe weergegee tydens produksie van die vokale /a:/ en /i:/ met normale en verhoogde luidheid

Figuur 2 vertoon 'n geleidelike verlaging in gem. fo van die vokale /a:/ en /i:/ vanafidie ouderdomsgroep 810 jaar tot by die ouderdomsgroep $30-40$ jaar. Hierdie verlaging in die gem. fo van vroue is nie so groot as die verlaging in gem. fo wat by mans in dieselfde tydperk voorkom nie. Die laagste gemiddelde fo-waardes word deur die groep 70-80 jaar vertoon. Die gemiddelde fowaardes van die verskillende ouderdomsgroepe verskil egter nie statisties, op 'n $5 \%$ peil van betekenis, nie.

Dit kom voor asof die invloed van veroudering nie eenvormige gem. fo veranderinge by alle vroue teweegbring nie, terwyl 'n styging in gem. fo by feitlik alle mans voorkom. Uit die literatuur blyk baie kontroversie rondom die invloed van veroudering op die gem. fo van vroue (McGlone \& Hollien, 1963) en sommige navorsers (Aronson, 1985), voel dat hierdie verskillende neigings nie verklaar kan word nie. Hollien (1987) postuleer egter dat menopouse die omgekeerde van puberteit is. Die neiging van mans se gem. fo om na die ouderdom van 50-60 jaar toenemend te begin styg en vroue se gem. fo wat neig om te daal, staan in die literatuur bekend as die "sentrale neiging" (Orlikoff, 1990b) wat Hollien (1987) se siening dat die menopouse die omgekeerde effek as puberteit op gem. fo het bevestig.

\section{- Vokaalverwante verandering in gem. fo van mans en vroue}

Soos dit blyk uit figure 1 en 2 is die gem. fo van /i:/ telkens hoër as vir/a:/. Die /i:/ is 'n hoë, voorvokaal en produksie van hierdie vokaal behels dat die tong gelig word. Met die oplig van die tong word die hioïedbeen en larinks opwaarts getrek en die laringale spiere word gestrek. Gevolglik verhoog die elastisiteit van die stembande en het hoër gem. fo waardes vir /i:/ tot gevolg (Arónson, 1985).

\section{Luidheidsverwante veranderinge in gem. fo van} mans en vroue

Fonasie met verhoogde luidheid het telkens hoër gem. fo-waardes as normale fonasie tot gevolg. Hierdie verhoging in gem. fo tydens harde fonasie kan gesien 
word as die resultaat van veranderinge in o.a. subglottale lugdruk wat vir klankpeilvariasie benodig word.

Tydens harde fonasie kom die grootste gem. foverhoging by die 70-80 jaar voor. Verskeie outeurs rapporteer'n toename in die veranderlikheid van gem. fo van bejaardes wat toegeskryf kan word aan 'n verlies aan aanpasbaarheid as gevolg van 'n vermindering in spiertonus en -krag, ossifikasie en ander ouderdomsverwante veranderinge in die bindweefsel van die laringale kraakbeen. (Hollien, 1987; Colton \& Casper, 1990; Orlikoff, 1990a; Biever \& Bless, 1989; Brown et al., 1989).

\section{PIEK-TOT PIEK FREKWENSIEFLUKTUASIE}

Statisties betekenisvolle verskille kom nie by die piek-tot-piek frekwensiefluktuasie (PPFF) ("jitter")waardes van mans en vroue voor nie. Om hierdie rede word die verkreë resultate gekombineer en weergegee in figuur 3.

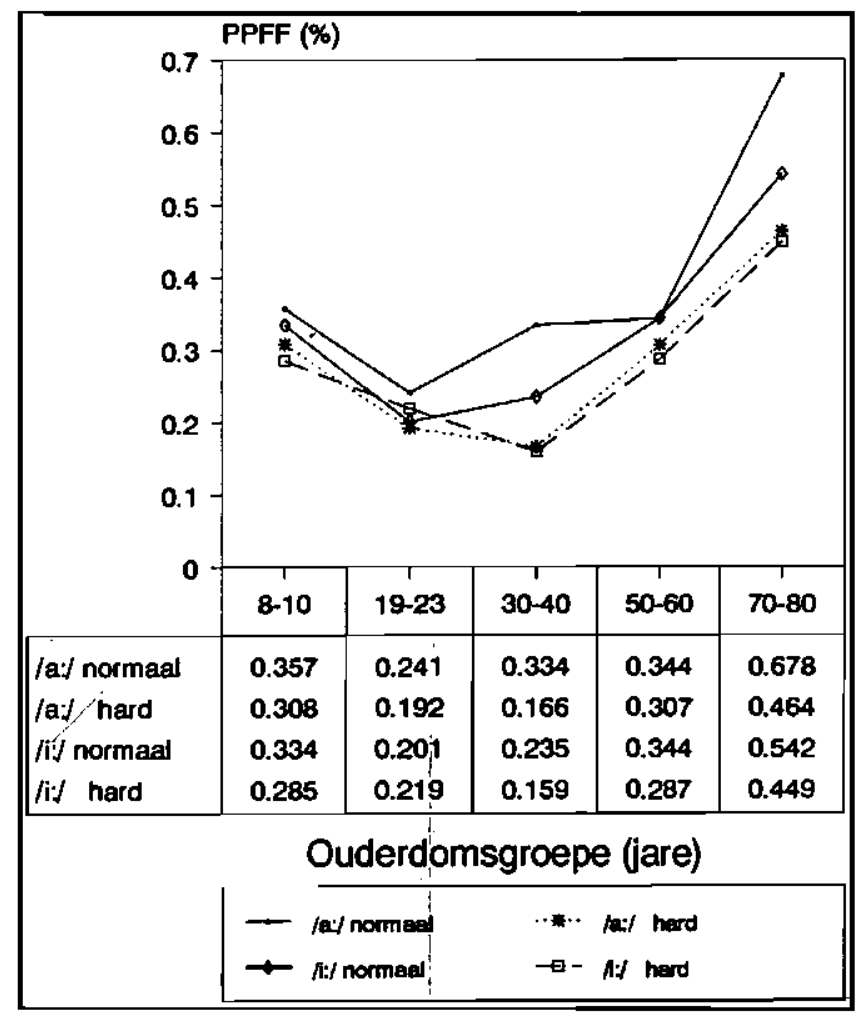

Figuur 3:PPFF-waardes van mans en dames in verskillende ouderdomsgroepe tydens produksie van /a:/en/i:/ met normale en verhoogde luidheid.

\section{- Ouderdomsverwante verandering in PPFF}

Lae PPFF-waardes reflekteer relatief hoë stabiliteit in stembandvibrasie. Die groep 19-23 jaar verkry dan ook die laagste gemiddelde PPFF-waarde vir /a:/ en /i:/, wat dui op die mees stabiele stembandvibrasie van al die ouderdomsgroepe. Orlikoff (1990a) rapporteer dat liggaamsfunksionering maksimum effektiwiteit tussen 20-29 jarige ouderdom bereik. Die lae PPFF-waardes van die groep 19-23 jaar korrelleer dan ook met hierdie stelling van Orlikoff. Teen dertigjare ouderdom begin homeostatiese funksionering, sowel as kompensatoriese en regulatoriese kontrole in die liggaam afneem. PPFF bereik dan ook'n maksimum gemiddelde waarde (figuur 3) by die groep 70-80 jaar en verskil statisties betekenisvol, op 'n $5 \%$ peil van betekenis, van die ander ouderdomsgroepe. Hierdie hoër PPFF-waardes wat korreleer met 'n toename in ouderdom dui dus op 'n geleidelike verlies in stabiliteit in stembandvibrasie en word geassosieer met growwe, skor en hees stemme (Hollien, 1987; Horii, 1980; Orlikoff, 1990a).

Alle bejaardes vertoon nie hoë PPFF-waardes nie. Hierdie verskynsel word in die literatuur verklaar aan die hand van die fisiese gesondheid van die proefpersone, veral wat betref kardiovaskulêre gesondheid (Biever \& Bless, 1989; Brown et al., 1989; Orlikoff, 1990b). Orlik off (1990a) vind dat gesonde, bejaarde mans se PPFF ooreenstem met die PPFF van mans in hul twintigerjare, terwyl bejaarde mans met aterosklerose baie hoër PPFF-waardes as die gesonde jong en bejaarde mans vertoon. Dit is dus duidelik dat sekere gesondheidsverwante faktore PPFF-resultate kan beïnvloed. Dit is verder ook bekend dat alle liggaamlike sisteme nie ewe vinnig verouder nie en dat laringale veroudering by sommige persone vinniger as by ander kan plaasvind (Chodzko-Zajko \& Ringel, 1987). By die opstel van normatiewe riglyne moet die wye omvang van PPFF-waardes van bejaardes dus ingedagte gehou word en kan groepsgemiddelde nie sonder meer op die geriatriese populasie toegepas word nie.

\section{- Vokaalverwante verandering in PPFF}

Die verskillende vokale het nie 'n statisties betekenisvolle invloed op PPFF nie, alhoewel dit voorkom asof /a:/ meer konstante resultate oplewer. Hierdie resultate korreleer ook met die van Wilcox \& Horii (1980).

\section{- Luidheidsverwante veranderinge in PPFF}

Uit die resultate van PPFF blyk dit dat fonasie met verhoogde luidheid feitlik konstant laer waardes oplewer as fonasie met normale luidheid. Glaze et al. (1990) postuleer dat luidheidsveranderinge teweeggebring word deur veranderinge in subglottale lugdruk en die mediale kompressie van die stembande wat gevolglik die stembandvibrasiepatroon verander deur verlenging van die geslote fase van stembandvibrasie. Die veranderinge wat in die spraakproduksiemeganisme plaasvind vir harde fonasie kan dus moontlik bydra tot groter stabiliteit in die vibrasiepatroon van die stembande en lewer gevolglik laer PPFF-waardes op.

\section{PIEK-TOT.PIEK AMPLITUDEFLUKTUASIE}

Geen statisties betekenisvolle verskille kom by die piek-tot-piek amplitudefluktuasie (PPAF) ("shimmer")waardes van die twee geslagte voor nie en daarom word mans en dames se resultate gekombineerd in figuur 4 weergegee. Figuur 4 stel die verandering van $P P A F$ met toename in ouderdom voor, vir die vokale /a:/ en /i:/ tydens produksie met normale en verhoogde luidheid.

\section{- Ouderdomsverwante veranderinge in PPAF}

Die PPAF-waardes van die verskillende ouderdomsgroepe verskil nie statisties, op 'n $5 \%$ peil van betekenis, 


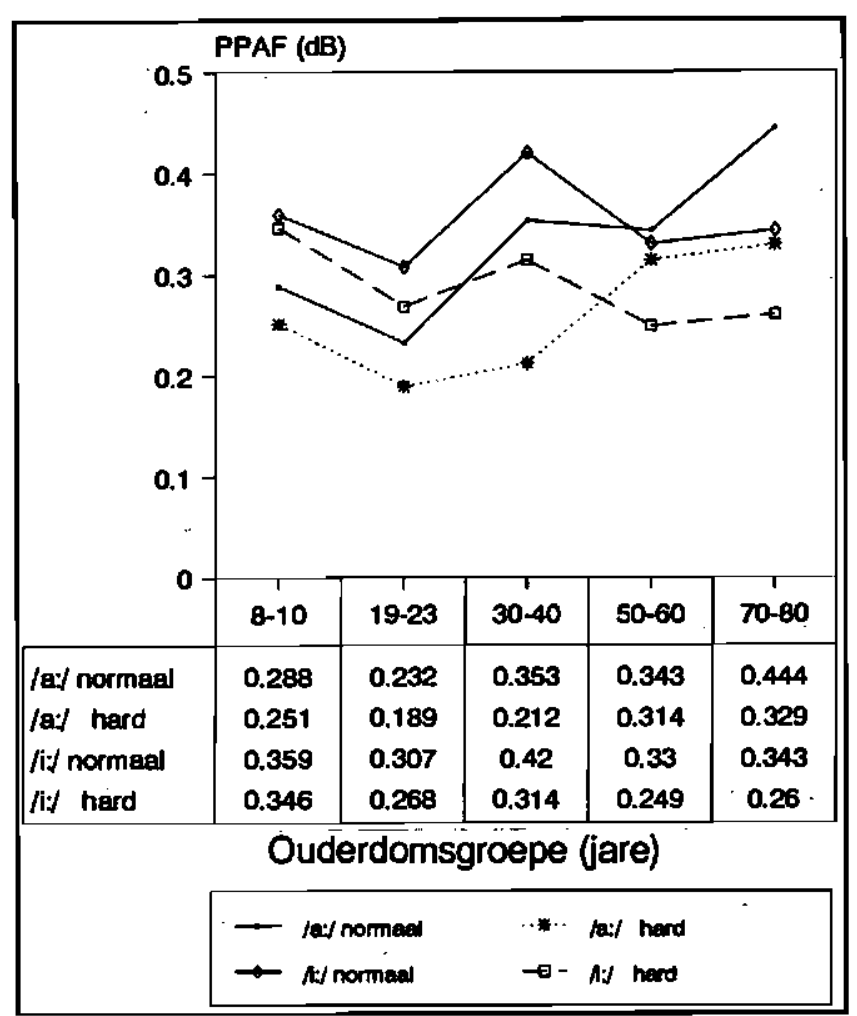

Figuur 4: PPAF-waardes van mans en dames in verskillende ouderdomsgroepe tydens produksie van /a:/ en /i:/ met normale en verhoogde luidheid.

van mekaar nie. Lae PPAF-waardes reflekteer 'n hoë mate van reëlmaat in stembandvibrasie. Die groep 1923 jaar behaal vir beide vokale /a:/ en /i:/ die laagste PPAF-waardes wat dui op die mees reëlmatige stembandvibrasie van al die ouderdomsgroepe. Hierdie resultate korreleer met Orlikoff (1990a) se stelling dat maksimum effektiwiteit in liggaamsfunksionering ongeveer in die tydperk $20-29$ jaar plaasvind. Glaze et al. (1990) vind dat PPAF-waardes vir kinders 5-11 jaar buite die PPAF-waardes van volwassenes lê. Die groep 8-10 jaar van die huidige studie, vertoon ook hoër waardes by kinders op grond van voortdurende anatomiese en morfologiese struktuurveranderinge op hierdie ouderdom. Tydens die maak van opnames vir die huidige studie is ook gevind dat opnames oor die algemeen moeiliker vir kinders as volwassenes gemaak word, a.g.v. moeiliker elektrodeplasing. 'n Swak golfpatroon is ook in sommige gevalle verkry, wat die gevolg kan wees van meer vetweefsel in die nek wat algemeen by kinders voorkom (Colton \& Conture, 1990; Baken, 1987), maar ook die gevolg van swak elektrodekontak op die klein en hooggeplaaste larinks. Hierdie veranderlikes dra moontlik by tot die hoër PPAF- en PPFF-waardes wat vir kinders in die huidige, sowel as ander studies verkry is (Colton \& Conture, 1990; Glaze et al., 1990).

Net soos die geval by PPFF, korreleer die hoër gemiddelde PPAF-waardes met ' $n$ toename in ouderdom en dui op 'n geleidelike verlies aan reëlmaat in stembandvibrasie soos wat 'n persoon verouder. Hoë PPAF- en PPFF-waardes is direkte korrelate van 'n growwe, skor en hees stem, en kan verwag word dat die verouderende stem toenemend grof, skor en hees sal klink. Dit is egter nie altyd die geval nie. Tydens die huidige studie behaal sommige bejaardes PPAF-waardes wat korreleer met die waardes van die groep 19-23 jaar. Net soos die geval by PPFF kan die afleiding gemaak word dat fisiese gesondheid met stemfunksie verband hou. Alhoewel die proefpersone van die huidige studie gesond was, is faktore soos arteriosklerose en osteoporose nie spesifiek gekontroleer nie. Hierdie veranderlikes, wat nie in dieselfde mate by die bejaarde proefpersone voorkom nie, kon ook moontlik bydra tot hoër PPAF- (en PPFF)-waardes (Chodzko-Zajko \& Ringel, 1987; Brown et al., 1989; Orlikoff, 1990b).

\section{- Vokaalverwante veranderinge in PPAF}

By vergelyking van PPAF-resultate van /a:/ en /i:/ blyk dit dat die vokaal /a:/ beter is om te gebruik vir die meting van PPAF as /i:/, aangesien dit voorkom asof /i:/ meer onkonstante resultate oplewer as /a:/. Hier kan onkonstante PPAF-resultate van /i:/ moontlik toegeskryf word aan die opwaartse verplasing van die larinks tydens produksie van $/ i: /$, aangesien die elektrodes spesifiek geplaas word vir produksie van die vokaal /a:/ en nie vir /i:/-produksie aangepas word nie.

\section{- Luidheidsverwante veranderinge in PPAF}

Figuur 4 toon aan dat fonasie met verhoogde luidheid telkens laer PPAF-waardes as normale fonasie tot gevolg het. Dit wil voorkom asof die veranderinge wat in die stemproduksie-meganisme vir fonasie met verhoogde luidheid plaasvind, bydra tot groter reëlmaat in stembandvibrasie en gevolglik laer PPAF-waardes oplewer as normale fonasie. Dit is dus duidelik uit huidige resultate dat stemluidheid gekontroleer moet word tydens metings.

\section{HARMONIEK/RUIS-VERHOUDING}

Die H/R-verhoudingswaardes (H/R-verhouding) van mans en vroue verskil nie statisties betekenisvol, op 'n peil van $5 \%$ betekenis, van mekaar nie en daarom is die resultate gekombineer en weergegee in figuur 5. Figuur 5 stel die verandering in $H / R$-verhouding met veroudering vir die vokale /a:/ en /i:/ tydens produksie met normale en verhoogde luidheid voor.

\section{- Ouderdomsverwante veranderinge in $\mathbf{H} / \mathbf{R}$ - verhouding}

In figuur 5 is dit duidelik dat H/R-verhoudingswaardes ' $n$ dalende tendens met veroudering vertoon. Die H/R-verhoudingswaardes verskil nie statisties, op 'n $5 \%$ peil van betekenis, vir die groepe $8-10,19-23,30$ 40 en 50-60 jaar nie. Die H/R-waardes van die $70-80$ jaar groep, vir fonasie teen normale luidheid, verskil wel statisties betekenisvol van die ander groepe. In teenstelling met PPFF en PPAF reflekteer' $n$ hoër H/Rverhouding beter stembandfunksionering. Volgens Yumoto (1988) is die H/R-verhouding 'n goeie aanduiding van die graad van heesheid wat in die stem voorkom, aangesien die H/R-verhouding aandui in hoe 'n mate die harmoniese komponent deur die ruiskomponent in die stem verplaas word. Uit figuur 5 wil dit dus voorkom asof ouderdomsverwante involusie van die laringale strukture heesheid tot gevolg kan hê, en moontlik tot 


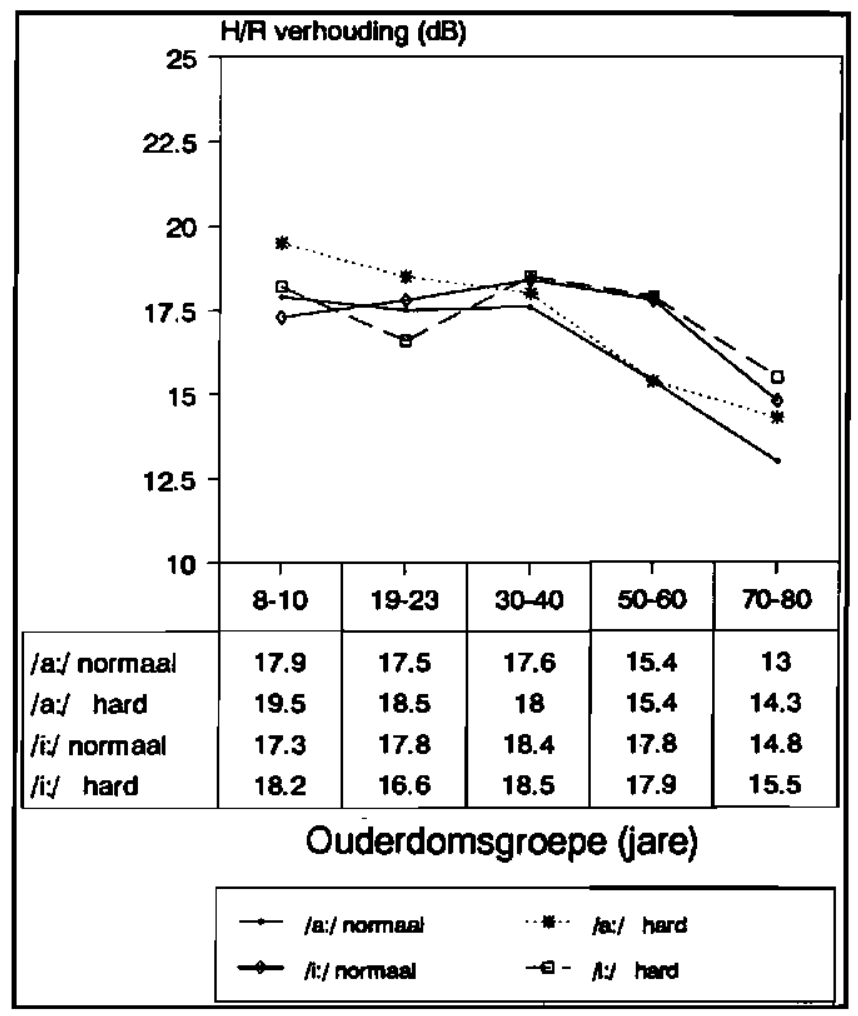

Figuur 5: Die H/R-verhoudingswaarde van persone in verskillende ouderdomsgroepe tydens produksie van /a:/ en /i:/ met normale en verhoogde luidheid.

perseptuele verskille tussen ou en jong stemme bydra (Shipp \& Hollien, 1969; Hollien, 1987). Alle bejaarde persone behaal egter nie lae $H / R$-verhoudingswaardes in die huidige studie nie. Soos in die geval by PPFF en PPAF kan die afleiding gemaak word dat alle persone se laringale strukture nie dieselfde mate van involusie met veroudering ondergaan nie (Chodzko-Zajko \& Ringél, 1987), en dat heesheid eerder met patologie van dié larinks as met veroudering verband hou.

\section{- Vokaalverwante verandering in H/R-verhouding}

Soos dit blyk uit die resultate van PPAF, PPFF en ook H/R-verhouding, lewer die vokaal /a:/ meer konstante resultate op as $/ \mathrm{i} \%$. Die meeste studies wat H/R-verhouding ondersoek, gebruik dan ook die vokaal /a:/ vir opnames (Yumoto, 1988).

\section{- Luidheidsverwante verandering in H/R-ver- houding}

Uit figuur 5 blyk dit dat hoër gemiddelde H/Rverhoudingswaardes telkens vir harde fonasie as vir normale fonasie behaal word. Dit blyk dus dat harde fonasie telkens beter stemband-funksionering tot gevolg het as normale fonasie.

\section{- AANDUIDINGS VIR DIE DAARSTELLING VAN 'N NORMATIEWE BASIS}

Die resultate van die gemiddelde fo-waardes vir mans en vrouens word o.g.v. die betekenisvolle statistiese verskille tussen die 2 groepe, afsonderlik beskou.
Hoewel slegs die 8-10-jaar-groep van die mans statisties, op 'n $5 \%$ peil van betekenis, van die ander ouderdomsgroepe verskil, word die gegewens vir die verskillende ouderdomsgroepe nogtans afsonderlik verskaf. Dit word gedoen na aanleiding van vorige navorsingsbevinding wat daarop dui dat luisteraars perseptuele verskille tussen ouderdomsgroepe waarneem. (Horii \& Ryan, 1981; Biever \& Bless, 1989; Brown et al., 1989). Gegewens van gemiddelde fo-waardes, word verskaf in bylaag 1 . 'n Statistiese berekening van $95 \%$ vertrouensintervalle is nie vir die gem. fo-waardes gedoen nie, omdat die data vir mans en vroue nie gekombineer kon word nie en die groepe gevolglik te klein was.

'n Normatiewe basis vir verskillende ouderdomsgroepe betreffende PPFF-, PPAF- en H/R-verhoudingswaardes word verskaf in bylae 2,3 en 4 respektiewelik. Die resultate van mans en vroue kan gekombineer word omdat geen betekenisvolle verskil bestaan nie. Die gegewens vir elke parameter is verkry deur statistiese berekenings van vertrouensintervalle, wat geld vir $95 \%$ van die populasie. Aangesien die produksie van /a:/ deurgaans meer konstante en betroubare resultate gelewer het, is dié waardes vir 'n normatiewe basis geselekteer. Die verkreë resultate van PPFF-, PPAF- en H/R-verhoudingswaardes korreleer met dié van ander navorsers en kan dus as betroubaar aanvaar word. (Horii, 1980; Kay Elemetrics Corp., 1989; Brown et al., 1989; Wilcox \& Horii, 1980; Orlikoff en Kahane, 1991; Glaze et al., 1990).

\section{GEVOLGTREKKINGS}

Uit die resultate van die huidige studie kan die volgende afleidings gemaak word:

- Gem. fo-waardes van mans en vrouens verskil betekenisvol. Gem. fo van mans vertoon 'n kurviliniêre verloop met ouderdom, naamlik 'n betekenisvolle verlaging in gem. fo vanaf $8-10$ jaar tot 3040 jaar, waarna geleidelike styging in gem. fo met verdere veroudering plaasvind. Individuele verskille kom egter voor. Die gem. fo van vroue verlaag ook vanaf die ouderdomsgroep 8-10 jaar tot en met 30-40 jaar, maar met toenemende ouderdom vind egter een van drie veranderinge plaas naamlik min verandering, 'n effense verlaging of eers 'n verlaging en dan 'n verhoging.

- Geen statisties betekenisvolle verskille kom vir PPFF, PPAF en H/R-verhouding van mans en dames voor nie. Een normbasis kan dus vir mans en dames per ouderdomsgroep opgestel word.

- PPFF en PPAF verhoog met veroudering terwyl die H/R-verhouding verlaag. Individuele verskille kom egter, veral by die geriatriese populasie, voor.

- Die vokaal /a:/ lewer meer konstante resultate op as die vokaal /i:/ vir PPFF, PPAF en H/R-verhouding en behoort dus as basis vir ouderdomsnorme gebruik te word.

- Fonasie met verhoogde luidheid veroorsaak hoër gem. fo-waardes, laer PPFF- en PPAF-waardes en hoër H/R-verhoudingswaardes as fonasie met normale luidheid.

'n Normbasis vir die onderskeie parameters is daargestel op grond van die statistiese berekening van 95\%-vertrouensintervalle, wat gebruik is om 'n skatting te mak van die onbekende populasiegemiddeld. 


\section{SLOT}

Die huidige studie is 'n kwantitatiewe analise van sekere stemparameters d.m.v. EGG. Resultate van die studie dra by tot die UP-Spraaknavorsingslaboratorium se beskikbare analisemetodiek deur die daarstelling van 'n normatiewe basis (sien bylaes 1 tot 4) vir gebruik in die kliniese en navorsingsituasie. Alhoewel subjektiewe evaluasie van die stem steeds noodsaaklik is, moet die stem ook objektief geanaliseer word sodat perseptuele, organiese en akoestiese data mekaar aanvul en sodoende 'n meer omvattende diagnostiese en terapeutiese metodiek daarstel.

\section{VERWYSINGS}

Aronson, A.E. (1985). Clinical voice disorders: an interdisciplinary approach. (2nd Ed.). New York: Thieme Inc.

Baken, R.J. (1987). Clinical measurement of speech and voice. Boston: College-Hill Press.

Biever, D.M. \& Bless, D.M. (1989), Vibratory characteristics of the vocal folds in young adult and geriatric women. Journal of Voice. 3(2), 120-131.

Bowerman, B.L. \& O'Connell, R.T. (1990). Linear Statistical Models. An applied approach (2nd Ed.). Ohio: Miami University.

Brown, W.S., Morris, R.J. \& Michel, J.F. (1989). Vocal jitter in young adult and aged female voices. Journal of Voice, 3(2), 113-119.

Childers, D.G. \& Lee, C.K. (1991). Vocal quality factors: analysis, synthesis, and perception. Journal of the Acoustical Society of America, 90(5), 2394-2410.

Chodzko-Zajko, W.J. \& Ringel, R.L. (1987). Physiological aspects of aging. Journal of Voice, 1(1), 18-26.

Colton, R.H. \& Casper, J.K. (1990). Understanding voice problems: A physiological perspective for diagnosis and treatment. Baltimore: Williams \& Wilkins.

Colton, R.H. \& Conture, E.G. (1990). Problems and pitfalls of electroglottography. Journal of Voice, 4(1), 10-24.

Fitch, J.L, (1990). Consistency of fundamental frequency and perturbation in repeated phonations of sustained vowels reading and connected speech. Journal of Speech and Hearing Research, 55, 360-363.

Glaze, L.E., Bless, D.M. \& Susser, R.D. (1990), Acoustic analysis of vowel and loudness differences in children's voices. Journal of Voice, 4(1), 37-44

Gould, W.J. (1988). The clinical voice laboratory: Clinical application of voice research. Journal of Voice, 1(4), 305309.

\section{Bylae 1}

Guy, R.F., Edgley, C.E., Arafat, I, \& Allen, D.E. (1987). Social Research Methods: Puzzles and Solutions. Boston: Allyn \& Bacon, Inc.

Hollien, H. (1987). "Old Voices": What do we really know about them? Journal of Voice, 1(1), 2-17.

Horii, Y. (1980). Vocal shimmer in sustained phonation. Journal of Speech and Hearing Research, 23, 202-209.

Horii, Y. \& Ryan. W J (1981). Fundamental frequency characteristics and perceived age of adult male speakers. Folia Phoniatrica, 33, 227-233.

Kay Elemetrics Corp. (1989). DSP Sona-Graph(tm), model 5500/5500-1 Operating Manual - Issue E. Pine Brook, NJ Kay Elemetrics Corporation.

Lieberman, R. (1963). Some acoustic measures of the fundamental periodicity of normal and pathologic larynges. Journal of the Acoustical Society of America, 35(3), 344. 353.

Linville, S.E., Korabic, E.W. \& Rosera, M. (1990). Intra. production variability in jitter measures from elderly speakers. Journal of Voice, 4(1), 45-51.

McFarlane, S.C. \& Watterson, T.L. (1991). Clinical use of the laryngograph and the electroglottogram (EGG) with voice disordered patients. Seminars in Speech and Language, $12,108-113$.

McGlone, R.E. \& Hollien, H. (1963). Vocal pitch characteristics of aged women. Journal of Speech and Hearing Research, $6,164-170$.

Orlikoff, R.F. (1990a). Heartbeat-related fundamental frequency and amplitude variation of healthy young and elderly male voices. Journal of Voice, 4(4), 322-328.

Orlikoff, R.F. (1990b). The relationship of age and cardiovascular health to certain acoustic characteristics of male voices. Journal of Speech and Hearing Research, 33, 450 457.

Orlikoff, R.F. \& Kahane, J.C. (1991). Influence of mean sound pressure level on jitter and shimmer measures, Journal of Voice, 5(2), 113-119.

Sataloff, R.T., Spiegel, J.R., Carroll, L.M., Darby, K.S. Hawkshaw, M.J. \& Rulnick, R.K. (1990). The clinical voice laboratory: Practical design and clinical application. Journal of Voice, 4(3), 264-279.

Shipp, T. \& Hollien, H. (1969). Perception of the aging male voice. Journal of Speech and Hearing Research, 12, 703709 .

Smit, G.J. (1983). Navorsingsmetodes in die gedrags wetenskappe. Pretoria: HAUM-Opvoedkundige Uitgewers.

Steyn, A.G.W., Smit, C.F. \& Du Toit, S.H.C. (1987). Moderne statistiek vir die praktyk. Pretoria: J.L. van Schaik (Edms.) Bpk.

Wilcox, K.A. \& Horii, Y. (1980), Age and changes in ivocal jitter. Journal of Gerontology, 35(2), 194-198.

Yumoto, E. (1988). Quantitative assessment of the degree of hoarseness. Journal of Voice, 1(4), 310-313.

Normatiewe aanduidings vir gem. fo van mans en vroue in verskillende ouderdomsgroepe tydens normale en harde fonasie van /a:/

\begin{tabular}{|l|c|c|c|c|c|}
\hline \multirow{2}{*}{$\begin{array}{l}\text { Vokaal } \\
\text { a:/ }\end{array}$} & Ouderdomsgroep & \multicolumn{2}{|c|}{$\begin{array}{c}\text { Gem. fo (Hz) met } \\
\text { normale fonasie }\end{array}$} & \multicolumn{2}{c|}{$\begin{array}{c}\text { Gem. fo (Hz) met harde } \\
\text { fonasie }\end{array}$} \\
\cline { 2 - 6 } & & $\begin{array}{l}\text { Laagste } \\
\text { waarde }\end{array}$ & $\begin{array}{c}\text { Hoogste } \\
\text { waarde }\end{array}$ & $\begin{array}{l}\text { Laagste } \\
\text { waarde }\end{array}$ & $\begin{array}{c}\text { Hoogste } \\
\text { waarde }\end{array}$ \\
\hline \multirow{4}{*}{ Mans } & & 237.3 & 290.7 & 240.8 & 310.29 \\
& $19-10$ & 99.2 & 150.4 & 103.7 & 164.1 \\
& $30-40$ & 108.3 & 126.6 & 125.9 & 140.7 \\
& $50-60$ & 84.4 & 167.5 & 94.9 & 191.4 \\
Vroue & $70-80$ & 111.2 & 181.6 & 122.9 & 198.5 \\
& $8-10$ & 250.1 & 314.2 & 274.2 & 338.1 \\
& $19-23$ & 216.8 & 323.5 & 221.3 & 330.1 \\
& $30-40$ & 194.9 & 249.7 & 196.1 & 249.4 \\
\hline
\end{tabular}


Bylae 2

Normatiewe aanduidings vir die hoogste en laagste PPFF-waardes (“jitter”) vir persone in verskillende ouderdomsgroepe tydens normale en harde fonasie van /a:/

\begin{tabular}{|c|c|c|c|c|c|}
\cline { 3 - 6 } \multicolumn{2}{c|}{} & \multicolumn{2}{c|}{$\begin{array}{c}\text { PPFF (\%) met } \\
\text { normale fonasie }\end{array}$} & \multicolumn{2}{c|}{$\begin{array}{c}\text { PPF (\%) met harde } \\
\text { fonasie }\end{array}$} \\
\hline \multirow{2}{*}{ Vokaal } & $\begin{array}{c}\text { Ouderdoms- } \\
\text { groep }\end{array}$ & $\begin{array}{l}\text { Laagste } \\
\text { waarde }\end{array}$ & $\begin{array}{c}\text { Hoogste } \\
\text { waarde }\end{array}$ & $\begin{array}{c}\text { Laagste } \\
\text { waarde }\end{array}$ & $\begin{array}{c}\text { Hoogste } \\
\text { waarde }\end{array}$ \\
\hline \multirow{4}{*}{ /a:/ } & $8-10$ & 0.251 & 0.464 & 0.194 & 0.423 \\
& $19-23$ & 0.212 & 0.27 & 0.163 & 0.221 \\
& $30-40$ & 0.184 & 0.484 & 0.123 & 0.208 \\
& $50-60$ & 0.228 & 0.459 & 0.216 & 0.397 \\
\end{tabular}

\section{Bylae 3}

Normatiewe aanduidings vir die hoogste en laagste PPAF-waardes ("shimmer") vir persone in verskillende ouderdomsgroepe tydens normale en harde fonasie van /a:/

\begin{tabular}{|c|c|c|c|c|c|}
\cline { 3 - 5 } \multicolumn{2}{c|}{} & \multicolumn{2}{c|}{$\begin{array}{c}\text { PPAF (dB) met } \\
\text { normale fonasie }\end{array}$} & \multicolumn{2}{c|}{$\begin{array}{c}\text { PPAF (dB) met harde } \\
\text { fonasie }\end{array}$} \\
\hline Vokaal & $\begin{array}{c}\text { Ouderdoms- } \\
\text { groep }\end{array}$ & $\begin{array}{l}\text { Laagste } \\
\text { waarde }\end{array}$ & $\begin{array}{c}\text { Hoogste } \\
\text { waarde }\end{array}$ & $\begin{array}{c}\text { Laagste } \\
\text { waarde }\end{array}$ & $\begin{array}{c}\text { Hoogste } \\
\text { waarde }\end{array}$ \\
\hline \multirow{4}{*}{ /a:/ } & $8-10$ & 0.185 & 0.391 & 0.173 & 0.328 \\
& $19-23$ & 0.158 & 0.305 & 0.132 & 0.244 \\
& $30-40$ & 0.226 & 0.479 & 0.154 & 0.269 \\
& $\mathbf{5 0 - 6 0}$ & 0.224 & 0.461 & 0.175 & 0.453 \\
\end{tabular}

\section{Bylae 4}

Normatiewe aanduidings vir die hoogste en laagste $H / R$-verhoudingswaardes vir persone in verskillende ouderdomsgroepe tydens normale en hárde fonasie van /a:/

\begin{tabular}{|c|r|c|c|c|c|}
\multicolumn{2}{c|}{} & & \multicolumn{2}{c|}{$\begin{array}{c}\text { H/R-verhouding (dB) } \\
\text { normale fonasie }\end{array}$} & \multicolumn{2}{c|}{$\begin{array}{c}\text { H/R-verhouding } \\
\text { (dB) }\end{array}$} \\
\cline { 3 - 6 } Vokaal & $\begin{array}{c}\text { Ouderdoms- } \\
\text { groep }\end{array}$ & $\begin{array}{c}\text { Laagste } \\
\text { waarde }\end{array}$ & $\begin{array}{c}\text { Hoogste } \\
\text { waarde }\end{array}$ & $\begin{array}{c}\text { Laagste } \\
\text { waarde }\end{array}$ & $\begin{array}{c}\text { Hoogste } \\
\text { waarde }\end{array}$ \\
\hline \multirow{4}{*}{ /a:/ } & $8-10$ & 15.3 & 20.7 & 17.4 & 21.7 \\
& $19-23$ & 14.9 & 20.1 & 16.6 & 20.4 \\
& $30-40$ & 15.2 & 19.9 & 15.9 & 20.1 \\
& $50-60$ & 13.2 & 17.7 & 12.8 & 17.9 \\
\hline
\end{tabular}




\section{INFORMATION FOR CONTRIBUTORS}

The South African Journal of Communication Disorders publishes reports and papers concerned with research, and critically evaluative theoretical and philosophical conceptual issues dealing with aspects of human communication and its disorders; service provision; training; and policy.

The South African Journal of Communication Disorders will not accept material which has been published elsewhere or that is currently under review by other publications.

\section{MANUSCRIPT STYLE AND REQUIREMENTS}

Manuscripts should be accompanied by a covering letter providing the author's address and telephone numbers. All contributions are required to follow strictly, the style specified in the Publication Manual of the American Psychological Assoc. (3rd ed., 1983)(APA Pub. Man.), with complete internal consistency. Four copies of triple-spaced high quality type-written manuscripts with numbered pages, and wide margins should be submitted. They should be accompanied by ONE identical disc copy of the paper; (1) in Wordperfect 5.1 (with an extension .wp5). Filenames should include the first author's initials and a clearly identifiable keyword or abbreviation thereof and should be typewritten on the last line of the last page of the Reference List (for retrieval purposes only).

As a rule, contributions should not exceed much more than 30 pages, although longer papers will be accepted if the additional length is warranted. The firs page of TWO copies should contain the title of the article, name of author(s), and institutional affiliation (or address). In accordance with the APA Pub. Man. style (1833, p.23) authors are NOT required to provide qualifications. In the remaining two copies, the first page should contain only the title. The second page of all copies, should contain only an abstract (100 words), written in English and Afrikaans. Afrikaans abstracts will be provided for overseas contributors. Major headings where applicable should be in the order of METHOD, RESULTS, DISCUSSION, CONCLUSION, ACKNOWLEDGEMENTS, REFERENCES. All paragraphs should be indented.

TABLES AND FIGURES which should be prepared on separate sheets (one per page), should be copied for review purposes and only the copies sent initially. Figures, graphs, and line drawings that are used for publication however, must be originals, in black ink on good quality white paper, but these will not be required until after the author has been notified of the acceptance of the article. Lettering appearing on these should be uniform and professionally done, allowing for a $50 \%$ reduction in printing. On no account should lettering be typewritten on the illustration. Any explanation or legend should appear below it and should not be included in the illustration. The titles of tables, which appear above, and figures, which appear below, should be concise but explanatory. Both should be numbered in Arabic numerals in order of appearance. The number of illustrative materials allowed, will be at the discretion of the Editor (usually about 6).

\section{REFERENCES}

References should be cited in the text by surname of the author and the date, e.g., Van Riper (1971). Where there are more than two authors, after the first occurrence, et al. after the first author will suffice, except for six or more when $e t$ al. may be used from the start. The names of all authors should appear in the Reference List, which should be listed in strict alphabetical order in triple spacing at the end of the article. All references should be included in the List, including secondary sources, (APA Pub. Man. 1983, p.13). Only acceptable abbreviations of journals may be used, (see DSH ABSTRACTS, October; or The World List of Scientific Periodicals). The number of references should not exceed much more than 30 , unless specifically warranted.

\section{EXAMPLES}

Locke, J.L. (1983). Clinical psychology: The explanation and treatment of speech sound disorders. J. Speech Hear. Disord., 48 339-341.

Penrod, J.P. (1985). Speech discrimination testing. In J. Katz (Ed.), Handbook of clinical audiology (3rd ed.). Baltimore: Williams \& Wilkins.

Davis, G.A. \& Wilcox, M.J. (1985). Adult aphasia rehabilitation: Applied pragmatics. San Diego, CA: College-Hill.

\section{EDITING}

Acceptable manuscripts may be returned to the author for revision. Additional minor changes may also be made at this stage, but a note on the manuscript acknowledging each alteration made by the author, is required. The paper is then returned to the editorial committee for final editing for style, clarity and consistency.

REPRINTS: 10 reprints without covers will be provided free of charge.

DEADLINE FOR CONTRIBUTIONS: the preferred date is the 31st May each year, but papers will be accepted until 30th June by arrangement.

QUERIES, CORRESPONDENCE \& MANUSCRIPTS: should be addressed to The Editor, South African Journal of Communication Disorders, South African Speech-Language-Hearing 'Association, P.O. Box 31782, Braamfontein, 2017, South Africa. 


\section{INLIGTING WIR BPRAERS}

Die Suid-Afrikaanse Tydskrif vir Kommunikasieafwykings publiseer verslae en artikels wat gemoeid is met navorsing, of handel oor krities evaluerende, teoretiese en filosofiese konseptuele kwessies wat oor menslike kommunikasie en kommunikasieafwykings; diensverskaffing; opleiding en beleid gaan.

Die Suid-Afrikaanse Tydskrif vir Kommunikasieafwykings sal nie artikels aanvaar wat reeds elders gepubliseer is, of wat tans deur ander publikasies oorweeg word nie.

\section{MANUSKRIP STYL EN VEREISTES:}

Manuskripte behoort deur 'n dekkingsbrief vergesel te word wat die skrywer se adres en telefoonnommers bevat. Daar word van alle bydraers verwag om die styl, soos gespesifiseer is in die "Publication Manual of the American Psychological Assoc. (3rd ed., 1983) (APA Pub. Man."), nougeset te volg met volledige interne ooreenstemming. Manuskripte moet getik, van hoë gehalte en in drievoud spasiëring met wye kantlyne wees. Vier kopieë van die manuskrip moet verskaf word. EEN hiervan moet 'n identiese skyfkopie van die artikel wees in "Wordperfect" 5.1 (met'n uitbreiding wp5). Lêername behoort die eerste skrywer se voorletters en 'n duidelike identifiseerbare sleutelwoord of afkorting daarvan in te sluit en moet op die laaste lyn van die bladsy van die verwsyingslys getik word (slegs vir naslaan doeleindes)

As 'n reël moet bydraes nie 30 bladsye oorskry nie, maar langer artikels sal aanvaar word indien die addisionele lengte dit regverdig. Op die eerste bladsy van TWEE van die afskrifte moet die titel van die artikel, naam van die skrywer(s), en instansie (of adres) verskyn. In ooreenstemming met die "APA Pub. Man." se styl word daar NIE van skrywers verwag om enige kwalifikasies te verskaf nie. Op die eerste bladsy van die twee oorblywende afskrifte moet slegs die titel van die artikel verskaf word. Die tweede bladsy van alle afskrifte moet slegs 'n opsomming (100 woorde) in beide Engels en Afrikaans bevat. Afrikaanse opsommings sal vir buitelandse bydraers voorsien word. Hoofopskrifte moet, waar van toepassing, in die volgende volgorde verskaf word: METODE, RESULTATE, BESPREKINGS, GEVOLGTREKKINGS, ERKENNINGS en VERWYSINGS. Alle paragrawe moet ingekeep word.

TABELLE EN FIGURE wat op afsonderlike bladsye (een bladsy per tabel/illustrasie) moet verskyn, moet vir referent doeleindes gekopieer word en slegs die kopieẻ moet inisieel verskaf word. Figure, grafieke en lyntekeringe wat vir publikasie gebruik word, moet egter oorspronklike weergawes wees en moet in swart ink op wit papier van 'n hoë gehalte wees. Die oorspronklikes sal slegs verlang word nadat die artikel vir publikasies aanvaar is. Letterwerk wat op bogenoemde verskyn, moet eenvormig wees, professioneel gedoen word en daar moet in gedagte gehou word dat dit leesbaar moet wees na 'n 50\% verkleining in drukwerk. Letterwerk by illustrasies moet onder geen omstandighede getik word nie. Verklarings of legendes moet nie in die illustrasie nie, maar daaronder, verskyn. Die opskrifte van tabelle (wat bo-aan verskyn), en die onderskrifte van figure, (wat onderaan verskyn), moet beknop, maar verklarend wees. Numering moet deur middel van Arabiese syfers geskied. Tabelle en figure moet in die volgorde waarin hulle verskyn, genommer word. Die aantal tabelle en illustrasies wat ingesluit word, word deur die Redakteur bepaal (gewoonlik nie meer as 6 nie).

\section{VERWYSINGS}

Verwysings in die teks moet voorsien word van die skrywer se van en die datum, b.v., Van Riper (1971). Wanneer daar egter meer as twee skrywers is, moet daar na die eerste verskaffing van al die outeurs, van et al. gebruik gemaak word. In die geval waar daar egter ses of meer outeurs ter sprake moet et al. van die begin af gebruik word. Al die name van die skrywers moet in die Verwysingslys verskyn wat aan die einde van die artikel voorkom. Verwysings moet alfabeties in trippel spasiëring gerangskik word. Al die verwysings moet in die Verwysingslys verskyn, insluitende sekondêre bronne, ("APA Pub. Man." 1983, p.13). Slegs aanvaarbare afkortings van tydskrifte se titels mag gebruik word, (sien "DSH ABSTRACTS, October"; of The World List of Scientific Periodicals"). Die aantal verwysings moet nie meer as 30 oorskrei nie, tensy dit geregverdig is.

\section{LET OP DIE VOLGENDE VOORBEELDE:}

Locke, J.L. (1983). Clinical psychology: The explanation and treatment of speech sound disorders. J. Speech Hear. Disord., $48,339-341$.

Penrod, J.P. (1985), Speech discrimination testing. In J. Katz (Ed.), Handbook of clinical audiology (3rd ed.). Baltimore: Williams \& Wilkins

Davis, G.A. \& Wilcox, M.J. (1985). Adult aphasia rehabilitation: Applied pragmatics. San Diego, CA.: College-Hill.

\section{REDIGERING}

Manuskripte wat aanvaar is, mag na die skrywer teruggestuur word vir hersiening. Addisionele kleiner veranderinge mag ook op hierdie stadium aangebring word, maar'n nota ter aanduiding van alle veranderinge wat op die manuskrip voorkom, moet verskaf word. Die artikel word dan aan die redaksion ele komitee vir finale redigering van styl, duidelikheid en konsekwentheid teruggestuur.

HERDRUKKE: 10 herdrukke sonder omslae sal gratis aan die outeurs verskaf word.

SLUITINGSDATUM VIR BYDRAES: Bydraes word verkieslik teen 31 Mei elke jaar verwag, maar artikels sal nog tot 30 Junie vir aanvaarding oorweeg word.

NAVRAE, KORRESPONDENSIE EN MANUSKRIPTE: moet geadresseer word aan Die Redakteur, Die Suid-Afrikaanse Tydskrif vir Kommunikasieafwykings, Die Suid-Afrikaanse Spraak-Taal-Gehoor Vereniging, Posbus 31782, Braamfontein, 2017, Suid-Afrika. 